\title{
PROGRAMAS TUTORIAIS PARA OS CURSOS DE ENFERMAGEM ${ }^{1}$
}

\author{
Rosita Saupe ${ }^{2}$ \\ Lorena Teresinha Consalter Geib ${ }^{3}$
}

Saupe R, Geib LTC. Programas tutoriais para os cursos de enfermagem. Rev Latino-am Enfermagem 2002 setembro-outubro; 10(5):721-6.

A implementação dos Projetos Político-Pedagógicos, impulsionada pelas políticas de educação e saúde, gerou a necessidade de incorporar à matriz curricular vários programas para atender aos interesses e necessidades emanados dos cursos de graduação. Um deles é o Programa Tutorial, destinado a amparar o aluno como sujeito da educação e do cuidado. Nessa perspectiva, este estudo objetiva contribuir com a proposição e avaliação de um modelo tutorial, que possa preencher as lacunas detectadas no processo de construção dos Projetos Político-Pedagógicos. Para tanto, o artigo descreve o modelo teórico idealizado, com vistas a sua inclusão nos cursos de graduação.

DESCRITORES: enfermagem, currículo

\section{TUTORIAL PROgRAMS FOR NURSING COURSES}

The implementation of political-pedagogical projects, encouraged by health and education policies, generated the need to incorporate in nursing curricula several programs to attend the interests and necessities of undergraduate courses. One of these is the Tutorial Program that aims at considering the student as the subject of the education and care. In this way, this study aimed at contributing to the evaluation of a tutorial model in order to fill in gaps found in the process of construction of politicalpedagogical projects. Therefore, the article describes the idealized theoretical model with the purpose to include it in undergraduate nursing programs.

DESCRIPTORS: nursing, curriculum

\section{PROgRAMAs tutoriales PARA los CURsos de enfermería}

La implementación de los proyectos político-pedagógicos, impulsados por las políticas de educación y salud, generó la necesidad de incorporar a la matriz curricular varios programas para atender los intereses y necesidades que surgieron de los cursos de formación universitaria. Uno de ellos es el Programa Tutor, destinado a amparar al alumno como sujeto principal de la educación y del cuidado. En ésta perspectiva, este estudio tiene por objetivo contribuir con la proposición y evaluación de un modelo tutorial, que pueda llenar los vacíos detectados en el proceso de la construcción de los Proyectos político-pedagógicos. Para esto, este articulo describe el modelo teórico idealizado, con la perspectiva de ser incluido en los cursos de pregrado.

\footnotetext{
${ }^{1}$ Este tema é um dos sub projetos interinstitucionais em desenvolvimento pelo Grupo de Pesquisa em Educação em Enfermagem e Saúde, com financiamento do CNPq para o período 2001/2003; ${ }^{2}$ Enfermeira, Doutor em Enfermagem - USP, Pesquisador CNPq - UFSC, Programa de PósGraduação em Enfermagem, Departamento de Enfermagem da Universidade Federal de Santa Catarina, e-mail: saupe@amja.org.br; ${ }^{3}$ Enfermeira, Professor Titular da Universidade de Passo Fundo, Coordenadora do Educare - Grupo de Estudo e Pesquisa em Educação e Cuidado em Enfermagem, Mestre em Enfermagem - UFSC, e-mail: geib@ginet.com.br
} 


\section{INTRODUÇÃO}

As políticas públicas definidas para a educação na área da saúde, fundamentadas na Lei de Diretrizes e Bases da Educação Nacional (LDB), nas Diretrizes Curriculares (DC) e no Sistema Único de Saúde (SUS), precisam ser consolidadas por meio dos Projetos PolíticoPedagógicos dos Cursos (PPP). Por outro lado, o Grupo de Pesquisa em Educação em Enfermagem e Saúde, que tem como objeto central de suas investigações a graduação, vem acompanhando o planejamento, implantação e avaliação de cursos, o que lhe dá autoridade para afirmar a inexperiência da maioria dos cursos em trabalharem nessa perspectiva.

Essa constatação, aliada à experiência acumulada em pesquisa, ensino e assessorias, gerou a proposição de um modelo orientador da construção de $\operatorname{PPP}^{(1)}$. Encaminhado ao CNPQ para apreciação, o modelo foi aprovado, contemplado, inicialmente, com bolsas e, posteriormente, com recursos originários do Plano Sul de Pesquisa e Pós Graduação. Sua implementação como projeto integrado interinstitucional, envolvendo 10 (dez) universidades e grupos de pesquisa, a partir de março de 1999, tem gerado muitos dados como resultado do trabalho direto com cursos de enfermagem da Região Sul.

Uma das importantes contribuições, originárias do processo de desenvolvimento do referido projeto, diz respeito à ampliação que vem sofrendo o entendimento do que deve ser contemplado num PPP: da limitação original ao que denominávamos "grade curricular", hoje passa a representar todas as metas dos cursos, incorporando antigas e novas necessidades. Assim, o tema abordado neste artigo representa uma das ramificações dessa nova perspectiva, a saber, Programas Tutoriais.

\section{PROJETO POLÍTICO-PEDAGÓGICO EXPANDIDO}

O Plano Decenal de Educação para Todos e a LDB deslocam a política educacional brasileira de um planejamento burocrático e centralizado para um processo de descentralização administrativa e pedagógica, que se consubstancia na construção do Projeto PolíticoPedagógico como instrumento de expressão da autonomia escolar.

O Projeto Político-Pedagógico constitui um processo participativo de decisões que, por meio de uma forma inovadora, organiza o trabalho pedagógico, "buscando eliminar as relações competitivas, corporativas e autoritárias, rompendo com a rotina do mando pessoal e racionalizado da burocracia e permitindo as relações horizontais no interior da escola"(2).

Na medida em que se legitima pelo esforço coletivo e comprometido de todos os envolvidos com a ação educativa, o Projeto Político-Pedagógico confere à escola sua identidade e permite a criação de novas formas de organização do trabalho pedagógico, a partir da sua singularidade $e^{(3)}$.

A Enfermagem, no exercício da autonomia conferida pela LDB, para a construção dos Projetos Político-Pedagógicos de seus cursos, tem procurado contemplar a questão da qualidade de ensino, entendendo que ela está no processo e que "os processos são, essencialmente, relações: relações da escola com as pessoas, as instituições e com a comunidade"(4). Nesse sentido, a construção do Projeto Político-Pedagógico deve "oportunizar a apropriação dos conhecimentos humanos e técnicos historicamente produzidos, na perspectiva de melhor contribuir para a inserção crítica [do aluno] no contexto das relações sociais, em nível macro, como um ser que se humaniza, cada vez mais"(4).

No PPP que estamos denominando de expandido, a Proposta ou Matriz Curricular permanece como central, incluindo os marcos Referencial, Filosófico e Conceitual, bem como a Estrutura do curso em termos de Missão, Objetivos, Perfil Profissiográfico, Matérias e Disciplinas, com suas ementas, programas e estratégias. Todavia vários programas estão sendo agregados como resultado de interesses e necessidades dos cursos.

Um programa bem atual está orientado para a Divulgação, visando dar visibilidade ao curso, tornandoo conhecido, tanto dentro como fora da Universidade ou Centro Universitário. A enfermagem é uma ação humana que, apesar da antigüidade de sua necessidade social, ainda é pouco conhecida enquanto profissão. Este programa tem o objetivo de orientar e estimular a procura pela profissão, torná-la conhecida na comunidade onde está inserida, divulgar sua história de lutas e conquistas, expandir o mercado e a oferta de postos de trabalho, confirmando a competência nos locais nos quais a participação de enfermeiros é imprescindível e veiculando outras possibilidades colocadas pelas necessidades do ser humano na contemporaneidade. 
Sentindo como muitos professores estão "assustados" com todas as exigências que se acumulam, verificamos a necessidade da implementação de programas de suporte e Capacitação, não somente para obtenção da titulação requerida pelo ensino superior, mas também de fomento da atualização para assumir o compromisso com o próprio PPP do curso. Porém mais importante, neste momento, parece-nos, é oportunizar a troca de experiências e momentos de vivência, pois a grande fonte de sofrimento dos docentes de enfermagem, hoje e segundo nossa percepção, é a competitividade que gera toda sorte de situações conflitantes nos grupos, inviabilizando o diálogo, a solidariedade, o compromisso grupal e interinstitucional. No "cada um por si", torna-se impossivel implementar inovações e concretizar metas coletivas. Essa situação, muito freqüente, gera perplexidade, principalmente quando relacionada a uma profissão que pretende cuidar de "humanos com humanização". Entendemos que este programa deve buscar ajuda de outros profissionais ou colegas externos à instituição e deve ter características de educação permanente.

Uma das maiores exigências colocadas aos docentes na atualidade é a produtividade em pesquisa. Foi-se o tempo em que aqueles que gostavam mais da docência restringiam-se à sala de aulas e aos campos clínicos. Hoje a pesquisa é uma exigência de manutenção de valores salariais e até de permanência no emprego. Ocorre que a maioria destes docentes, muitos, inclusive, com título de mestre, não têm tradição de pesquisa, requerendo que o PPP inclua um programa de Pesquisa e Produção Científica. Esse programa, também de caráter permanente, teria o objetivo de instrumentalizar e assessorar os docentes, por meio da organização e implementação de núcleos e grupos, orientados por linhas de pesquisa. Consideramos fundamental a existência, no quadro funcional, de pesquisadores experientes, respeitados pelo grupo, com trânsito nos órgãos de fomento, para a coordenação desse programa. Outro objetivo bem atual para esse programa diz respeito à instrumentalização dos docentes para a orientação de alunos de graduação em seus trabalhos de conclusão de curso. Essa exigência é nova nos currículos de enfermagem, poucos cursos a desenvolveram por iniciativa própria, e encontramos muitos docentes que estão "apavorados" com a perspectiva de ter de orientá-la. A ajuda advinda desse programa auxiliará não somente o professor a enfrentar esse desafio, mas possibilitará a produção de trabalhos e estudos mais consistentes por parte dos graduandos.

Afirmar a realidade como marco referencial para a formação de enfermeiros, mantendo dados atualizados sobre a região de inserção do curso, tanto do espaço urbano quanto rural, subsidiando a programação curricular e propostas de intervenção nesta realidade, visando às transformações que se apresentarem como necessárias, é o objetivo de um programa de Extensão. Mas, apesar da denominação, ultrapassa os programas assistencialistas freqüentemente desenvolvidos pelas universidades e, além de planejar, implementar e avaliar espaços para a troca de saberes e experiências junto às comunidades onde o curso desenvolve suas ações, promover enquetes para definir demandas de capacitação de enfermeiros docentes e assistenciais ou profissionais de áreas afins, em programas de pós graduação sensu lato e stricto, analisa expectativas do mercado, contribuindo para a inserção de egressos em postos de trabalho.

Outro importante programa promove a Avaliação dos vários programas que compõem o PPP, subsidiando a tomada de decisões quanto aos ajustes necessários. Avalia o ensino, a aprendizagem, os objetivos, o aluno, o professor, os egressos, a produtividade, as metas, as relações internas e externas, os compromissos assumidos, o impacto das propostas.

Ao lado dos programas descritos anteriormente, emerge, com a mesma prioridade, o Programa Tutorial. Por isso, vamos nos deter agora sobre ele, objeto central deste artigo.

\section{PROGRAMAS TUTORIAIS}

Ao refletir sobre a influência direta da graduação em enfermagem na determinação do perfil profissional, encontramos que "não é exercitado na escola, nem nos momentos de avaliação, esse ser sujeito que constrói, com compromisso, maturidade e ética, uma formação profissional que tenha o diálogo e a participação como base" ${ }^{\text {"(5) }}$. O que se constata é que o discurso da relação sujeito - sujeito não é vivenciado pelo aluno na escola. A relação estabelecida entre docente e aluno é de sujeitoobjeto. Esse entendimento é corroborado por outros estudos $^{(6-8)}$ ao referirem-se à relação educador/educando 
como unilateralmente autoritária, controladora e punitiva. As autoras defendem que se comece a problematizar essa temática "que nos encaminha a uma reflexão a respeito das diretrizes pedagógicas que vêm pautando a capacitação profissional no âmbito da saúde"(6).

$\mathrm{Na}$ tentativa de romper com esses modelos conservadores incrustados no fazer dos docentes e ir além dos discursos antagônicos, as escolas de enfermagem quedam-se, no momento, a redesenhar os perfis profissiográficos do enfermeiro, contemplando, além da dimensão técnica e político-emancipatória, também a dimensão hermenêutica, que possibilite o desenvolvimento de atitudes orientadas para a interlocução, para a atuação como educador cuidadoso e cuidador educado e de outros comportamentos de domínio afetivo ${ }^{(7)}$.

Contudo, percebe-se um vácuo pedagógico nos projetos em geral, no que tange ao amparo do aluno como sujeito de cuidado por parte da escola. Iniciativas isoladas, pontuais, surgem como possibilidades de recobrir o processo da formação do enfermeiro de componentes terapêuticos que possam, pela vivência de uma educação com cuidado, constituir-se em ação pedagógico - cuidativa. Entre essas ações, apontam-se os espaços terapêuticos ${ }^{(8)}$ e os programas tutoriais.

$\mathrm{Na}$ literatura consultada, são escassas as referências a esse respeito. Começam a despontar na medicina algumas investidas de "método tutorial". Uma delas o tutor descreve como "facilitador do aprendizado", referindo-se ao trabalho desenvolvido "por meio de resolução de problemas-chave com enfoque para a epidemiologia, para a ética médica e aspectos sociais voltados para a relação médico-paciente" ${ }^{\prime(9)}$. Com ênfase, portanto, no desenvolvimento das habilidades cognitivas e comunicativas, visando à melhor assistência ao cliente/ paciente. Com esse mesmo enfoque, há referência a um treinamento de tutores, com vistas à aplicação da aprendizagem baseada em problemas (ABP), realizado por professores americanos com 48 docentes de uma Faculdade de Medicina de São Paulo(10).

Na enfermagem, também são muito incipientes essas iniciativas. Numa delas ${ }^{(11)}$, ao relatarem os resultados da implantação de uma proposta alternativa de melhoria da qualidade do processo ensino-aprendizagem, testada com alunos de disciplinas profissionalizantes de enfermagem, por meio do acompanhamento, registro de seu desenvolvimento (progressivo ou regressivo) e encaminhamento para suporte de superação de dificuldades apresentadas, verificaram sua procedência, mas também as dificuldades para sua concretização de modo informal, quando dependente somente de boa vontade e compromisso pessoal dos envolvidos.

Borba, em sua dissertação de mestrado, partiu da afirmação que "o aluno de enfermagem, enquanto ser humano único, apresenta necessidades básicas, podendo estas serem afetadas e atendidas de diferentes maneiras, frente às situações que vivencia no cotidiano do curso de graduação"(8) . Assim, ofereceu um espaço terapêutico para o estudante colocar e discutir suas experiências e necessidades, concluindo pela necessidade de sua manutenção, já que favorece as relações e intercâmbio entre estudantes e docentes, possibilitando a busca "de alternativas consensuais para as situações vivenciadas e uma outra possibilidade de relação aluno-professor"(8).

Na Faculdade Santa Marcelina (SP), a preceptoria foi entendida como "uma estratégia de ensinoaprendizagem individualizada, que busca promover a integração de conhecimentos, habilidades e atitudes desenvolvidas pelo aluno, ao longo do curso, para desenvolver sua identidade profissional”(12). De amplo alcance, o programa atribui ao preceptor "facilitar a percepção, compreensão e ação do aluno, em direção à conquista de sua transformação em enfermeiro"(12).

Frente a essas limitações epistemológicas da dimensão hermenêutica da formação do enfermeiro, pretende-se avançar no desvelamento teóricometodológico e contribuir com a proposição e avaliação de um modelo tutorial que possa preencher as lacunas detectadas na construção dos Projetos PolíticoPedagógicos dos cursos de graduação.

Entendemos Programas Tutoriais como a disponibilização de recursos de apoio ao estudante, podendo desenvolver muitas perspectivas, conforme diagnóstico de necessidades reais detectadas no curso. Prevê atendimento aos alunos, de forma individual, grupal ou de turma, promovendo possibilidades de melhoria do desempenho acadêmico e de encaminhamento de problemas específicos de ajustamento, integração, exclusão. Todavia não deve ser entendido como "ajuda aos fracos", pois pretende também mobilizar capacidades adormecidas, incentivando o engajamento em grupos e projetos de pesquisa, extensão, monitoria, estágios extracurriculares, participação em eventos e iniciativas comunitárias. Investiga indicadores de qualidade de vida dos alunos e relaciona-os com as situações vividas no 
curso; promove possibilidades de flexibilização curricular; identifica situações de estresse vividas por estudantes em seu cotidiano escolar e classifica os modos utilizados para seu enfrentamento, gerando informações para a proposição de ações de intervenção.

Entendemos que cada curso deve construir sua proposta de Programa Tutorial aderida as suas necessidades e especificidades, conforme condições reais de operacionalização. Todavia, para não partir do nada e fundamentada pela experiência dos pesquisadores que atuam nos grupos que integram o consórcio coordenado pelo Grupo de Pesquisa em Educação em Enfermagem e Saúde (Home Page: www.ccs.ufsc.br/enfermagem/ educacao/) e de resultados de pesquisas que têm sido gerados nele, propomos um modelo teórico idealizado, que pode funcionar como ponto de partida para ilustrar possibilidades, orientar as discussões e gerar a problematização necessária para o avanço. O Programa Tutorial idealizado apresenta duas dimensões, as quais denominamos, respectivamente, de "Dimensão Educativa" e "Dimensão Cuidativa".

A dimensão educativa caracteriza-se por oferecer ao aluno programas de suporte pedagógico que o auxiliem a melhorar seu desempenho acadêmico, seja nas habilidades técnicas, na competência hermenêutica ou no desempenho de suas funções político emancipatórias. Todos esses programas terão o objetivo de instrumentalizar o aluno para o domínio de conhecimentos, habilidades e atitudes relacionadas aos conteúdos e experiências de aprendizagem já incluídas nos programas de ensino. Assim, a dimensão educativa do programa tutorial pretende funcionar como uma oportunidade de reforço, treinamento e desenvolvimento da capacidade de estudar e aprender com maior eficácia; instrumentalizar-se em técnicas e procedimentos; desenvolver a capacidade de comunicarse de forma oral ou escrita; e também de participar dos movimentos sociais em nível estudantil, das associações profissionais e da comunidade em geral. Não se destina somente a alunos com dificuldades, mas também àqueles que, com essa sustentação complementar, poderão distingüir-se, desenvolver pesquisas, ou seja, ir além dos mínimos necessários para a graduação. Essa dimensão vem sendo implementada em algumas instituições de ensino superior. Na USP, a Pró-Reitoria de Graduação promoveu em 1998 um Seminário para discutir o papel de Programas de Tutorias nos Cursos de Graduação como elemento de qualificação da vida acadêmica dos alunos, que culminou com a Portaria GR- $n^{\circ} 3150$, de 22 de março de 1999, contemplando atividades institucionalizadas de tutorias, de orientação acadêmica e de supervisão da aprendizagem dos estudantes.

A dimensão cuidativa, talvez a mais necessária neste momento, representa o próprio Programa Tutorial em ação, efetivando-se por meio de encontros dos tutores com as turmas pelas quais são responsáveis, tanto de forma coletiva, quanto de grupos de interesse ou atendimento individual. Na Universidade de Passo FundoRS, essa modalidade foi implantada em caráter experimental, por meio de ações pedagógico-assistenciais nos cursos vinculados ao Instituto de Ciências Biológicas. Desde o segundo semestre letivo de 1998, a idéia de ter um professor-tutor para cada turma de alunos foi discutida e acatada pelos coordenadores dos cursos de Enfermagem, Farmácia e Ciências Biológicas, e disseminada entre docentes e discentes.

Com a intenção de ilustrar o modelo teórico concebido, construímos a representação constante do quadro a seguir apresentado e que pretende ser uma síntese dos vários componentes considerados de forma a comporem uma totalidade orgânica.

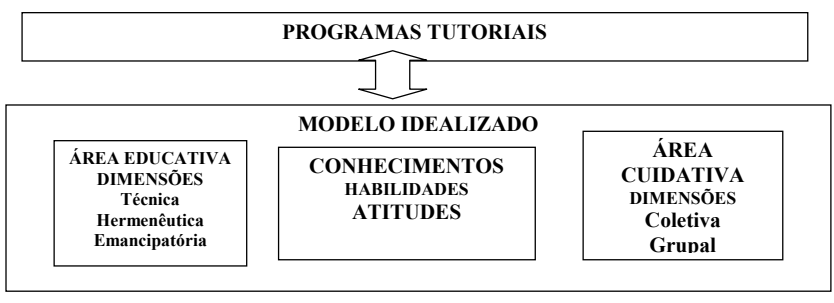

\section{CONCLUSÕES}

$\mathrm{Na}$ linha de montagem de qualquer fábrica, trabalha-se com o percentual de $0 \%$ de expectativa de fracasso em relação ao produto final. Por que então, ao trabalharmos com seres humanos, capital muito mais valioso e que retém as conseqüências amargas da reprovação e do insucesso, aceitamos, até esperamos, um índice de reprovação de $\mathrm{x} \%$ e ficamos desconfiados da qualidade do docente quando essa premonição não se concretiza? Nenhum professor quer, em sã consciência, atuar num curso onde seja proibido reprovar. Por outro lado, precisamos superar a lógica autoritária da avaliação, 
usada como mecanismo de controle e poder e que incorporou a reprovação como normal e fator de credibilidade do professor.

O Programa Tutorial apresentado como proposta neste artigo tem a intenção de contribuir para minimizar o sempre atual problema da avaliação, cercado por duas dimensões, uma que pretende transformar a relação professor-aluno num exercício de cuidado, e outra que oferece suporte complementar às dificuldades e potencialidades apresentadas pelos educandos.

\section{REFERÊNCIAS BIBLIOGRÁFICAS}

1. Saupe R, Alves, ED. Contribuição à construção de Projetos Político Pedagógicos na Enfermagem. Rev Latino-am Enfermagem 2000 abril; 8(2):60-7.

2. Veiga IPA, organizadora. Projeto político-pedagógico da escola: uma construção possível. Campinas (SP): Papirus; 1998.

3. Veiga IPA, Resende LMG, organizadoras. Escola: espaço do Projeto Político Pedagógico. Campinas (SP): Papirus; 1996.

4. Sousa JV. Avanços e Recuos na Construção do Projeto Político Pedagógico em Rede de Ensino. In: Veiga, IPA, Resende LMG, organizadoras. Escola: espaço do Projeto Político Pedagógico. Campinas (SP): Papirus; 1996. p.12757.

5. Fernandes GF, Vaz MRC. Processo de avaliação humanizada e participativa nos estágios supervisionados de enfermagem. Texto e Contexto Enf 1999 janeiro/abril; 8(1):106-21.

6. Colomé CM, Landerdahl MC, Olivo VF. Diretrizes pedagógicas na formação em saúde: buscando uma relação educador/educando de cunho transformador. Texto e Contexto Enf 1999 janeiro/abril; 8(1):166-76.

7. Saupe R, Tagliari MH, Madalosso A, Migott A, Scortegagna HM, Baruffi L, et al. Educadores-Educandos construindo o Projeto Político Pedagógico de um curso centrado no cuidado cultural. Texto e Contexto Enf 1999 janeiro/abril; 8(1):441-51. 8. Borba MR. Alunos e professora de Graduação em Enfermagem criando um espaço terapêutico: reinventando caminhos. [dissertação]. Florianópolis (SC): Programa de Pós Graduação em Enfermagem/UFSC; 1997.

9.Lopes LFZ, Cunha OR Jr, Haberkorn S. Método Tutorial no Internato da Faculdade de Ciências Médicas da Universidade de São Francisco. Rev Bras Educ Méd 1998 janeiro/abril; 22 (supl.):72.

10. Zanolli MB, Komatsu RS.Treinamento de tutores: iniciando um programa de aprendizagem baseado em problemas. Rev Bras Educ Méd 1998 janeiro/abril; 22(supl.):74.

11. Saupe R, Reibnitz KS. Programa de acompanhamento do aluno. Cogitare Enf 1997 janeiro/julho; 2(1):64-9.

12. Sanna MC, Silva GTR, Gomes PC. Programa de preceptoria do curso de graduação em Enfermagem da Faculdade Santa Marcelina. In: $51^{\circ}$ Congresso Brasileiro de Enfermagem, $10^{\circ}$ Congresso Panamericano de Enfermeria; 1999. outubro 2-7; Florianópolis, Santa Catarina. Florianópolis: Resumos; 1999. p.182. 